\title{
Exploration of Computer Network Teaching Based on Innovation Abilities Cultivation
}

\author{
Min Lai ${ }^{1, a}$ Yong $\mathrm{Xia}^{2, \mathrm{~b}}$ \\ ${ }^{12}$ Gannan Medical University, Ganzhou, Jiangxi, China, 341000 \\ aemail, ${ }^{b}$ email
}

Keywords: Computer Network Teaching, Innovation Abilities Cultivation, Exploration

\begin{abstract}
The cultivation of university students' innovation ability is the eternal theme of universities educational innovation. Teaching innovation is the heart and key to educational innovation. It advances to innovate teaching conception, optimizes teaching content, innovates teaching method, reforms experimental content and teaching evaluation in the course of reform practice in teaching computer network. It can achieve obvious results in teaching computer network. It can cultivate university student to build up innovation consciousness, enhance innovation spirit and improve innovation ability. It can train the senior technician with innovation ability and innovative thinking for society.
\end{abstract}

\section{Introduction}

In recent years, the popularity of network applications have been deep into the social, economic, and every corner of life, especially with the development of networking technology, networks are increasingly changing people's lives. Because of this, it requires a lot of technical personnel at all levels of the network society. In order to meet the needs of society, universities have stepped up efforts to train technical personnel on the network and the most direct expression of the experiment is to pay more attention to teaching computer network. Conventional computer network courses, more attention is to teach the theory, to equip students with the network architecture level, working principle, agreements. But society needs is not "on paper" theorists, but "veteran" doer. This requires us to do a good job teaching the theory at the same time, strengthen the experimental teaching, training the abilities of students through teaching, practice and innovative ability. Mission of higher education is to foster an innovative spirit and practical ability of senior specialized talents, development of science and technology and culture and promote socialist modernization. In the knowledge economy era, only with innovative consciousness, innovative spirit and ability of people can make a difference, to be successful. Development of knowledge economy depends on the ability to innovate and level of knowledge will, which requires colleges and universities training with innovative high-quality talent.

Increasingly wide range of applications in the computer network era, we need a computer network teacher teaching reform, will develop students' innovative ability to penetrate into the computer network curriculum reform; students cultivate talents with strong innovative spirit and ability in order in the increasingly social competition incentives make a difference, to get social recognition.

\section{The Teaching Status of Computer Network Course}

Most computer network course syllabus for college undergraduate nationwide requires students to master the basic principles of network communication and it focuses on computer network OSI / RM seven architectures and TCP / IP architecture. Course contents include basic concepts of computer networks, network architecture, and according to the network architecture and protocols are set forth the basic principles of the physical layer, data link layer, network layer, transport layer and application layer. Which focuses on the physical layer data communications infrastructure; data link layer protocol IEEE802.3 presentation; focuses on IP network layer protocol; TCP transport layer protocol describes; application layer describes TELNET, FTP, SMTP / POP3, DNS and other 
protocols.

Teaching in the computer network, the protocol is the core. The usual protocol teaching content from the basic functions of the protocol to the agreement details, including syntax, semantics, and synchronization. Therefore, lectures protocol details a lot, but to understand the essence of the agreement association agreement between the content, methods and techniques used protocol relative lack of student understanding of the basic principles of computer networks tend to stay in a variety of protocol specification details memory basis.

\section{The Innovation of Teaching Ideas Is a Prerequisite for Cultivating Innovative Talents}

Training students' creative ability in computer networking courses, computer network first requires innovative teaching ideas. Innovative Education requires teachers to students in the process of innovation in education, with its sense of innovation, creative thinking and innovative ability and other factors and promote the formation and development of students' creative ability, which requires teachers to change the "dignity of the division," "teacher authority "and other traditional concepts of education. Computer networks cannot be regarded as teaching textbook content, we cannot think of himself as the master of teaching activities to student-centered, jointly through the exchange of teachers and students, positive interaction and common interpretation of the contents of textbooks, co-discovered and solve problems, based on the order student, promote the development of its subject. To fully respect every student, not some fixed criteria to evaluate a student, every student fully discovered the bright spot and students of different personalities can give full play to their special talents. Form a lively student-centered learning situation, establish democracy, equality and the concept of teachers and students, to build mutual respect, mutual trust, mutual understanding of the relationship between teachers and students, and create favorable students' creative thinking and innovative ability of a suitable environment.

Innovations in teaching is to eliminate outdated and backward obsolete teaching content, to be able to facilitate people to create scientific knowledge and inventive spirit of the times and the development of people's creative potential as a teaching content. The development of computer technology and communication technology, computer network so that new knowledge is growing, in this case, the times, optimizing computer network curriculum teaching content is very necessary. Computer network theory must be combined with practical importance of theoretical analysis and application development with due introduces the latest computer network technology, thereby opening up their horizons.

\section{The Teaching Exploration Based on Innovative Ability Cultivation}

Update of Teaching Ideas. Change teaching concepts shall be based on the student as the main body to promote their development. In the teaching process, teachers more like a director, step by step guide students so that students and teachers cooperate with students and students together to complete the teaching requirements. In this context, teachers must accurately grasp the teaching of positive factors and student learning initiative, through a variety of ways and means to develop students' interest in learning, students change from passive learning fundamentally.

Reform of Teaching Content. Teaching content should focus on the principles and basic concepts of computer networks learning. Only then can effective compression classroom teaching hours, leaving students more space and self-reflection, practice opportunities, in order to foster the development of creative ability of students. Thus, the first computer network teaching computer networks should rise to the level of a computer network system to look at the composition of the application system guided by scientific theories, computer network systems analysis, function, structure and essential characteristics, using a variety of methods to study systems engineering Construction and application software programming specific network applications. Teaching content should constitute the system logical framework on the basis of the computer network system analysis, and through the analysis of the concept and nature of the problem, so that students learn not only knowledge, but also learn to analyze the problem. 
On this basis, according to the basic requirements of the curriculum and teaching 40 hours of classroom rules, we re-enact the teaching content: the computer network architecture, data communications infrastructure, technology and basic data link layer protocol commonly used LAN technology (IEEE802. 3), the network layer protocol and basic techniques (the IP protocol as an example), the transport layer protocol and basic concepts (with TCP as an example), and other network programming foundation. Application layer protocols and network reserved for students learning the latest technology. In particular the process of teaching, focusing on key basic theory to explain, using a variety of means and methods of teaching basic concepts, basic principles speak deep thoroughly publicize desalination detailed calculation derivation and a brief description, presentation content.

Reform of Teaching Methods and Means. In the teaching process, and give full play the main role leading role of teachers and students, by repealing "mouthpiece", "chalk and talk" the traditional teaching methods, implementation of the "import type", "heuristic," "self-learning", "discussion style" and other beneficial teaching methods students' creative ability.

"Import" teaching. Import teaching classroom teaching is very important in the early stages, cannot be ignored. Most of the students in Before learning how a computer network on the Internet is very familiar with, so we are in the first class to allow students to freely discuss their problems in the real network or the Internet, the departure from these problems, stimulate students network communication theory content of interest and improve the learning enthusiasm of theoretical knowledge. Thus, the teaching of the principles behind the content will play a multiplier effect. For example, for students in the dormitory often through a hub to share Internet access, but do not understand its principles. Through this part of the presentation, the students know about the initial LAN. Then, the teacher ED students raised several questions: What kind of equipment can also set up local area network cable alone two hosts can set up a LAN in the same local area network host's IP address should be how to configure many of these issues? The students will think, but cannot solve, so they want to know the solution as soon as possible. And so on, so that students with real-life problems of learning and thinking into the computer network of theoretical knowledge, so that their interest in computer network course is getting keener, the learning process will enhance the initiative.

"Heuristic" Teaching. At the beginning of each chapter we first proposed the communication problems in the process, and then inspire students to think:??? How to solve these problems which mature technology which can be used to solve the specific agreement on how to implement these techniques to learn the end of this chapter, and then back to see if the problem posed at the beginning. For example, when talking about layered architecture, to present the complexity of the communication process, what problems will arise during the communication, to ensure reliable communication, the method used to solve these problems? Can a simple protocol to solve? If not, how to solve? What is the general solution to a complex problem is? Can we solve the complex problems of communication and thinking this way? How to solve? Through this series of questions, and gradually inspire students to master the structure of thought layered system.

"Self-learning" teaching. Part of this may be a "self-learning" teaching method, that is, by the next class of students to complete the self-learning process, to give them some guidance through the submission of the report in the form of small teachers. In this way students are encouraged to make full use of libraries and network resources themselves to acquire knowledge to achieve the innovative ability. For example, we let the students through extracurricular computer network access to relevant documents, a report on the IPV6 protocol.

"Discussion" teaching. When explaining network programming, a "discussion" type mode, mainly to complete the review of teachers work, and actively guide students to participate in the actual programming process research and development, to discuss learning. In many cases, teachers do not know the students in the programming process may encounter problems while at the same angle as more clearly between students. Thus, before the programming classes, students are arranged programming tasks, and then to explain and demonstrate in the classroom. After the talks, the class is divided into two groups to discuss, analyze programming questions and discuss the best 
solution.

The diversification of teaching methods. Currently courses are basically using the computer network multimedia teaching, teaching teachers to use PPT presentation file, but most of the PPT courseware is only static. Computer Network Course abstract terminology, concepts and more difficult to understand, and the communication process itself is a dynamic process. Static text is often difficult to clearly describe the courseware. Course author's group introduced a large number of animation, motion video, sound and other forms of stimulation of students in a variety of senses and courseware, making abstract information visualization, to facilitate students 'understanding, increase students' interest in learning. For example, network architecture each layer protocol data unit and its packaging process is very abstract, traditional way of expression is difficult to express clearly. We use graphics and animation, can process each layer packaging demonstration out, both vivid and easy to understand and grasp. In addition, our school library introduced the horizon of knowledge - education video resource library, a large number of rich video educational materials. They for students of different ages, in different disciplines, produced a series of scientific and educational programs. These programs apply to the school's teaching and learning, you can get very good results.

\section{Conclusion:}

By reforming of teaching methods, we explore the teaching methods and means to mobilize the students' enthusiasm, initiative and creativity, not only enable students to master the basic concepts of computer networks, network hardware, typical network operating systems and architectures, basic communication theory, and learn WAN composition and application, understand the purpose of teaching the Internet function is more important it is to train students to identify problems, solve the problem and the purpose of innovation ability to meet national and local development needs for innovative talents.

\section{References}

[1] Jia Xinzhang, Li Jingyuan. Education Exploration, Vol. 6 (2014) No 53, p.25-26

[2] Wang Qunyong. Higher Education Research, Vol. 12 (2015) No 27, p.74-76

[3] Jing Jianfen. Chongqing University of Posts and Telecommunications, Vol. 30 (2011) No 19, p.144-145

[4] Wang Kuailiang. Laboratory Research and Exploration, Vol. 29 (2012) No 27, p.21-23

[5] Zhang Gongxu, Sun Jing. Education Exploration, Vol. 8 (2013) No 27, p.57-60

\section{江西省赣州市渡口路 7 号南阳东升 2 栋 2 单元 504 室}

手机号码: 13907078663 收件人: 赖敏 